Assiut Scientific Nursing Journal

http://asnj.journals.ekb.eg

http://www.arabimpactfactor.com

\title{
Fear and Anxiety Impacts of the Covid-19 among Primigravida versus Multigravida Pregnant Women
}

\author{
Hanaa Kamal Helmy ${ }^{1}$, Sahar Elbastawes $\mathbf{y}^{2}$ \& Safaa Ibrahim Ahmed ${ }^{3}$. \\ ${ }^{1 .}$ Assistant Professor at Maternal and Neonatal Health Nursing Department, Faculty of Nursing, Beni- Suef \\ University, Egypt. \\ ${ }^{2 .}$ Lecturer at Family and Community Nursing Department, Faculty of Nursing, PortSaid University, Egypt. \\ 3. Assistant Professor at Obstetrics and Gynecology Nursing Department, Faculty of Nursing, Sohag University, \\ Egypt.
}

\begin{abstract}
The presence of pandemic disease as COVID-19 may increase the risk of the disease among pregnant women which increased risk during pregnancy and can lead to several consequences such as increased fear and anxiety levels that more frequent in the third trimester. Aim: To evaluate the prevalence of fear and anxiety Impacts of the covid-19 among primigravida versus multigravida pregnant women. Design: A descriptive and comparative design. Setting: This study was conducted in Egypt at Sohag and Beni-Suef city. Sample: - A total of 300 pregnant women between 10 and 30 April 2020 by an online snowball sampling. Tools: Data were collected using three online questionnaires including A structured questionnaire, fear of COVID-19 Scale (FCV-19S), and Corona Disease Anxiety Scale (CDAS). Results: women' age ranged from 20 - 33 years, and that women were mostly between $20<30$ years in primigravida $(50.0 \%)$ and their mean age $20.10 \pm 7.68$ and (37.0\%) in multigravida which their mean age $22.10 \pm 9$. 88 , it was observed that $(61.3 \%)$ had severed fear levels in primigravida and $(51.2 \%)$ in multigravida. it was displayed that a significant positive relationship was observed between the level of W-DEQ-A and BAI scores $\quad(p=$ $0.000<0.05$ ). Conclusion: The majority of primigravida have experienced high and severe fear and anxiety scores towards childbirth compared to multigravida mothers.
\end{abstract}

\section{Keywords: Anxiety, Covid-19, Fear, Multigravida \& Primigravida.}

\section{Introduction}

Increasing anxiety and fear in individuals all over the world are associated with COVID-19 during pregnancy (WHO, 2020). Infectious disease epidemics is damaged the physical health of pregnant women, and have a negative psychological impact on them. The psychological consequences may persist and need to be recovered in a much longer time. As COVID-19 occurs suddenly, is highly contagious and no specific drugs and in the absence of treatment, the patient's condition deteriorates rapidly and may even be fatal that has caused a negative psychological effect on the general pregnant women health and making them more likely to develop fear, anxiety or depression (Qiao, 2020, Schwartz \& Graham, 2020).

Pregnant women are worried about fetal health and the outcome of childbirth during the prenatal period which is accompanied by maternal mental distress and associated with pregnancy itself. Besides the fear and anxiety resulted from pregnancy, also there are many risk factors associated with the high fear and anxiety prevalence during pregnancy (Bayrampour \& Tough, 2015). One of these factors that can affect the mental health of pregnant women is related to natural disasters (Feduniw et al., 2020).
The current COVID-19 pandemic that considered an example of a natural disaster, which more than 22 million people worldwide are suffering from it and more than 791,000 people died. (WHO, 2020). Restrictions related to the social distance that prevents having communication with relatives, friends, and others increase fear, stress, anxiety, and depression in people's daily lives (Mehta et al., 2020).

Pregnant women also are in challenges due to the responsibility of caring for other children and family members. On the other hand, the essential need to receive regular care from maternity services increases the risk of exposure to infection with viruses (Hussein, 2020). Pregnant women are more affected by the virus. So, coronavirus epidemics cause fear and anxiety among them in different parts of the world. Concerns, anxiety, and fear during pregnancy causes some side effects such as preeclampsia, depression, the increased nausea and vomiting during pregnancy, preterm delivery, low birth weight, and low Apgar score (Qiao, 2020). These changes can cause emotional instability and several problems such as fear and anxiety in pregnant women (Ebadi et al., 2017). 
Viral or bacterial pandemics endanger the general population; however, there are specific populations, such as children and pregnant women, who may be at a higher risk and more vulnerable to or more seriously affected by infectious diseases. Due to their specific susceptibility to some infectious diseases, pregnant women are considered to be a special population group because of the unique 'immunological' condition caused by pregnancy. Cardiopulmonary adaptive changes, such as increased heart rate and stroke volume and decreased pulmonary residual capacity, that occur during pregnancy can increase the risk of hypoxemia and lead to increased severity. Therefore, pregnancy poses many difficulties in determining how infectious diseases should be handled, avoided, and managed (Aluvihare et al., 2004).

In times of presence of an epidemic, pregnant women experienced a fear of getting infected with the virus/disease, infection fears, frustration, boredom, inadequate supplies, inadequate information, financial loss, and stigma resulting in anxiety, stress, and depression, etc. (Hall et al., 2008). Stress can be explained as a feeling of emotional and physical tension which arises from any event that threatens our lives infection fears, frustration, boredom, inadequate supplies, inadequate information, financial loss, and stigma." Some researchers also suggested long-lasting effects (Brooks et al., 2020).

It is surmised that pregnant women facing a pandemic with no vaccination would result in fear of the unknown making them anxious, stressed, and depressed. Keeping in mind the concerns regarding psychological distress raised around the Goyal et al., (2020) have argued for timely action on mental health during the Covid-19 pandemic. Furthermore, the World Health Organization (WHO, 2020) has also issued public interest guidelines to address psychological issues that may arise. What is alarming is the heightened fear related to the coronavirus culminating in people committing suicide (Goyal et al., 2020, Mamun \& Griffiths 2020).

Pregnancy is considered the most important event in the pregnant women's life. So, she does the best to maintain good health to bring a healthy baby that may cause stress and severe fear (Adams et al., 2019). During COVID-19, pregnant women who have medical conditions, such as diabetes or blood pressure, and those who are older or overweight, are also more likely to be at high risk and suffer severe health complications due to COVID-19. These findings required the need to take all precautions to avoid COVID-19 disease for pregnant women and recently pregnant women. Pregnant women with COVID-19 were more likely to give birth prematurely and that 1 in 4 of all babies born to women with COVID-19 may be admitted to a neonatal unit, Stillbirth and newborn death rates however were low (WHO, 2020).

Anxiety is accompanied pregnant women during pregnancy is found stressful as lead to many changes that occur during this period as mood swings, narrowing of interest, depression, feeling of loneliness and impatience are experienced during the last weeks of pregnancy ( $\mathbf{L i}$ and Graham, 2017). Fear of covid-19 during pregnancy is experienced by a lot of women. fear of loss of the baby's or the mother's life fear of disease, fear to have a premature child, have a child with mental retardation or congenital malformation, fear of operation, fear of family's undesirable attitude of the new environment (Adams et al., 2019).

Screening and recognizing the signs of anxiety disorders during the perinatal period are very important, Because If not identified and treated, they may have adverse effects on both mother and baby (Yucel et al., 2013). Pregnant women need to promote health, good personal hygiene, encourage physical activities, appropriate diet, and good sleep habits, and integrate such health promotion materials (Brazendale et al., 2017).

The main important role of midwives and nurses to provide health education program about covid -19 and its preventive measures to avoid infection and reduce physical and psychological problems, give emotional support by including a pregnant woman, in addition to, provide care and health education about a better pregnancy and delivery ( Yeniel, \& Kavlak, 2014). Hence, the present study was conducted to investigate and compare fear and anxiety Impacts of the covid-19 among primigravida versus multigravida pregnant women at Beni -Suef and Sohag city.

\section{Significance of the study}

Women had a high risk for a disease that leads to increased risk during pregnancy can lead to many consequences, and causing increased anxiety levels. The prevalence rate of pregnancy fear and anxiety varies from 15 to 23 percent (Vameghi et al., 2018). Fear and anxiety are the most common negative emotions during pregnancy, being more frequent in the third trimester especially with COVID-19 that increases the level of maternal fear and anxiety during the epidemic. The primigravida pregnant women who experienced COVID-19 for the first time or multigravida are had a lot of fears and anxieties about the baby and if she will be abnormal and unhealthy that affected progress of labor and may lead to decrease uterine contractions and slow of labor.

So this study was be held to evaluate the prevalence of fear and anxiety Impacts of the covid-19 among primigravida versus multigravida pregnant women 
Aim of the Study

This study aimed to evaluate the prevalence of fear and anxiety Impacts of the covid-19 among primigravida versus multigravida pregnant women.

\section{Research questions}

1. What is the fear and anxiety levels toward covid19 among primigravida pregnant women?

2. Is there is a relationship between fear and anxiety scores toward covid-19 among primigravida and multigravida pregnant women and their pregnancy?

\section{Subjects \& Methods \\ Research design}

A descriptive and comparative design was utilized in the present study.

\section{Setting}

This study was conducted in Egypt at Sohag and Beni-Suef city.

\section{Sampling}

Snowball sampling was be used in this study, the study sample included 300 pregnant women from primigravida and multigravida pregnant women from 10-30April 2020. The inclusion criteria were: their ages ranged from 20-40 years at gestational ages of between 30 and 40 weeks, primigravida and multigravida pregnant women who are educated and who are willing to participate in the study.

\section{Tools and techniques of data collection}

Data were collected using three questionnaires including a structured online questionnaire, fear of COVID-19 Scale (FCV-19S), and Corona Disease Anxiety Scale (CDAS). It was developed by the researcher after reviewing related literature. There were two tools used in the present study as the following:

Tool (I):- A structured questionnaire: It was composed of two parts:

Part (1): It includes personal data which consisted of 4 items related to age, educational level, occupation, and residence.

Part (2): It includes the obstetrical history of pregnant women; it consisted of 4 items about the number of gravida, past medical history, history of abortion, and gestational weeks.

\section{Tool (II):- Fear of COVID-19 scale (FCV-19S)}

Fear of the COVID-19 Scale (FCV-19S) consists of 7 items measuring the emotional fear reactions toward the COVID-19 pandemic, and it included these seven items:

1. I am most afraid of Corona

2. It makes me uncomfortable to think about Corona

3. My hands become clammy when I think about Corona

4. I am afraid of losing my life because of Corona

5. When I watch news and stories about Corona on social media, I become nervous or anxious.
6. I cannot sleep because I'm worried about getting to Corona.

7. My heart races or palpitates when I think about getting Corona

Scoring system

It is on a five-point Likert-type scale from 1 to 5 . The sum of the scores of these items shows a higher level of fear (7-35). Designing and testing the validity and reliability of this tool were done by Ahorsu et al. (2020) in Iran 2020. The scale's Cronbach's alpha was calculated as 0.82 . Tool (III):- Corona disease anxiety scale (CDAS) Corona related anxiety is an 18 item tool that measures corona-related anxiety in two dimensions, namely psychological symptoms and physical symptoms, and the items are answered on a Likert scale from zero to 3 . Each participant receives a score from 0 to 54 . The validity and reliability of this questionnaire have been assessed in Iran by Alipour et al., (2020). Moreover, the Cronbach's alpha for the whole questionnaire was reported $(\alpha=0.919)$.

\section{It included these 18 questions}

1. Thinking about Coronavirus makes me anxious

2. I feel tense when I think about the Coronavirus threat.

3. I am seriously worried about the prevalence of Coronavirus

4. I am afraid of contracting Coronavirus

5. I fear that I might contract Coronavirus anytime

6. Minor symptoms make me think that I am contracting the virus, and I start checking myself

7. I am concerned about transferring the virus to others around me

8. My anxiety about Coronavirus has interfered with my daily activities

9. The mass media focus on Coronavirus make me anxious

10. Thinking about Coronavirus has interrupted my sleep

11. I have lost my appetite because of thinking about Coronavirus

12. I get a headache when I think about Coronavirus

13. My body starts jittering when I think about Coronavirus

14. I get goosebumps when I think about Coronavirus

15. Coronavirus has become my nightmare

16. I have less physical activity because of my fear of Coronavirus

17. I find it hard to talk with others about Coronavirus

18. I feel my heart beating when I think about Coronavirus 


\section{Validity and reliability}

Face and content validity of the tools for clarity, comprehensiveness, appropriateness, and relevance by a board of five experts' professors in Obstetric and gynecological health nursing and community health nursing at Sohag university hospital with more than ten years of experience in the field were assessed; the board ascertained the face and content validity of the tools after modifications. Reliability was assessed through Cronbach's alpha reliability test $\alpha=85 \%$. The tools' reliability was estimated by using the Pearson correlation coefficient test to compare variables. The Pearson correlation coefficient for the variables ranged between $(\mathrm{P} .<0.5)$ and $(\mathrm{P} .<0.001)$, which indicated a highly significant positive correlation between variables of the subjects.

\section{Ethical considerations}

Each pregnant woman was informed about the aim and benefits of the study in the first part before starting the questionnaire where every pregnant woman could not be starting the questionnaire without consent to participate in data collection in the current study. Each pregnant woman informed them that participation in the study was voluntary and that they had the right to withdraw from the study at any time before completing the questionnaire with no consequences, without giving any reason and that their responses would be held confidentially.

Methods of data collection

Pilot study: It was carried out on $10 \%$ of pregnant women (30), for modification and clarification, and estimation of the time needed for data collection. The designed tool was tested on pregnant women. To fill in the sheets unclear items were clarified, unnecessary items were omitted and new items were added. Those who shared in the pilot study were excluded from the study sample.

\section{Fieldwork}

As known the Egyptian Government guidelines to pregnant women are to reduce face-to-face communication and home isolation, we used an online snowball sampling procedure to collect data from pregnant women during the period between 10 and 30 April 2020. We designed a structured questionnaire using Google forms, then, we shared the link to the questionnaire to numerous Facebook groups. Facebook is the most widespread social network among Egyptians. Respondents were asked to forward the questionnaire to their eligible friends in their social network contact lists.

\section{Statistical analysis}

Data was collected and analyzed by the computer program SPSS" version, 21 Chicago. The USA. Data expressed as mean, standard deviation, and number, percentage, so nonparametric methods were used. Mann Whitney U test, Kruskal-Wallis test and was used Person's correlation used to determine significance between variables in the same group. N.s $\mathrm{P}>0.05$ is no significant, $\mathrm{P}<0.05$ is significant, $\mathrm{P}<0.001$ is moderate significance and $\mathrm{p}<0.000$ highly significance.

et al., 2020).

\section{Results}

Table (1): Percentage distribution of the studied pregnant women according to their demographic characteristics

\begin{tabular}{|c|c|c|c|c|}
\hline \multirow{2}{*}{ Item } & \multicolumn{2}{|c|}{ Primigravida (150) } & \multicolumn{2}{|c|}{ Multigravida (150) } \\
\hline & No. & $\%$ & No & $\%$ \\
\hline \multicolumn{5}{|c|}{ Pregnant women ' age in years } \\
\hline Range & \multicolumn{4}{|c|}{$20-33$ years } \\
\hline$-20<30$ & 75 & 50.0 & 55 & 37.0 .0 \\
\hline$-30 \leq 40$ & 75 & 50.0 & 95 & 63.0 .0 \\
\hline Mean \pm Stander deviation & \multicolumn{2}{|c|}{$20.10 \pm 7.68$} & \multicolumn{2}{|c|}{$22.10 \pm 9.88$} \\
\hline \multicolumn{5}{|l|}{ - Women ' education } \\
\hline -Primary education & 28 & 19.0 & 22 & 15.0 \\
\hline -Secondary education & 84 & 56.0 & 102 & 68.0 \\
\hline -University education & 38 & 25.0 & 26 & 17.0 \\
\hline
\end{tabular}




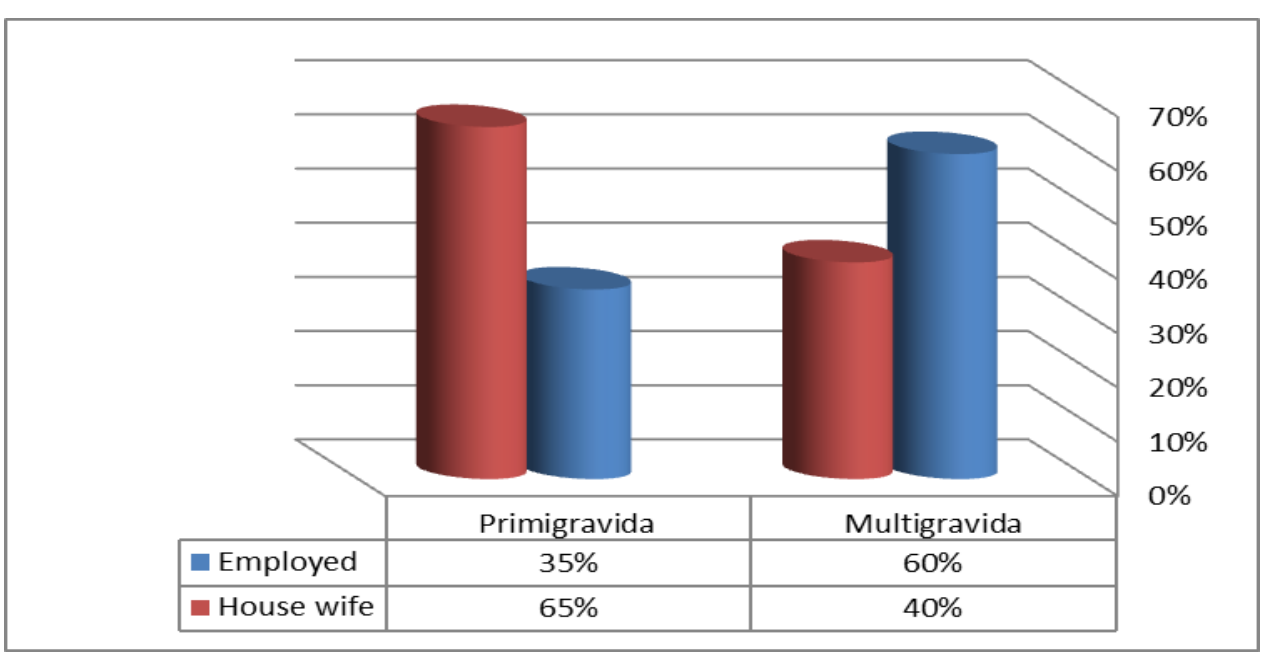

Figure (1): Percentage distribution of the studied pregnant women according to their occupation.

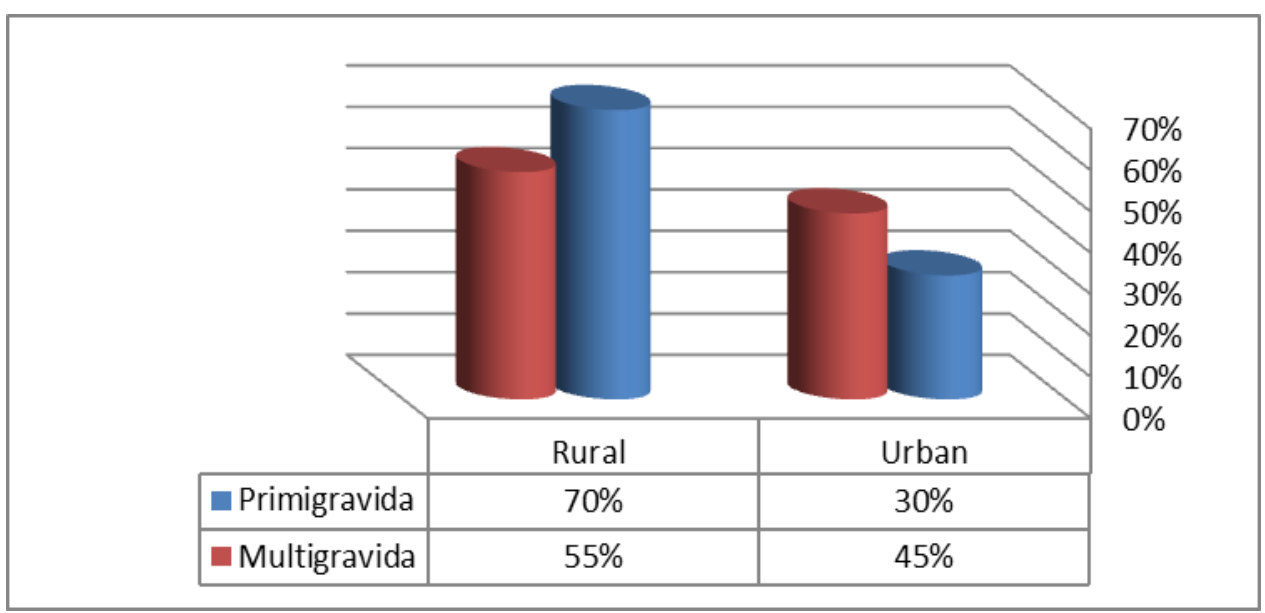

Figure (2): Percentage distribution of the studied pregnant women according to their residence

Table (2): Percentage distribution of the studied pregnant women according to their obstetrical history.

\begin{tabular}{|c|c|c|c|c|}
\hline \multirow{2}{*}{ Item } & \multicolumn{2}{|c|}{ Primigravida (150) } & \multicolumn{2}{|c|}{ Multigravida (150) } \\
\hline & No. & $\%$ & No. & $\%$ \\
\hline \multicolumn{5}{|l|}{ Number of gravidae } \\
\hline - $\quad$ Primigravida & 150 & 100.0 & - & - \\
\hline $\begin{array}{ll} & \text { Multigravida } \\
\end{array}$ & - & - & 150 & 100.0 \\
\hline \multicolumn{5}{|l|}{ Past medical history } \\
\hline$-\quad$ Yes & 0 & 0.0 & 10 & 7.0 \\
\hline$-\quad$ No & 150 & 100.0 & 140 & 93.0 \\
\hline \multicolumn{5}{|l|}{ Gestational weeks. } \\
\hline$-30<33$ & 30 & 20.0 & 22 & 15.0 \\
\hline$-\quad 33<37$ & 98 & 65.0 & 106 & 70.0 \\
\hline$-\quad 37 \leq 40$ & 22 & 15.0 & 22 & 15.0 \\
\hline
\end{tabular}




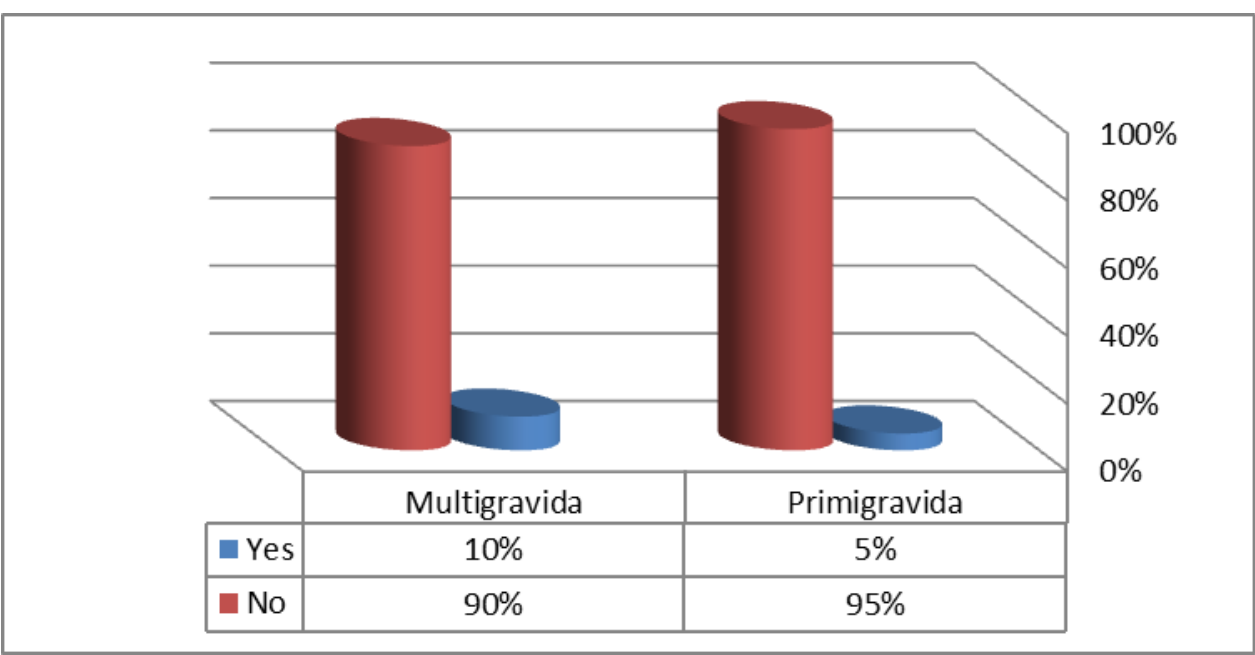

Figure (3): Percentage distribution of the studied pregnant women according to their history of abortion.

Table (3): Mean scores and standard deviations among primigravida and multigravida pregnant women for the Fear of COVID-19 scale factors.

\begin{tabular}{|c|c|c|c|c|}
\hline FCV-19S factors & Primigravida & Multigravida & X2 & p-value \\
\hline - Fear of COVID-19 scale average Scores & $28.70 \pm 5.12$ & $22.730 \pm 10.12$ & $\mathbf{2 7 . 1 5}$ & $\mathbf{0 . 0 0 0} * * *$ \\
\hline
\end{tabular}

$* * * A$ highly statistically significant difference $(P<0.000)$

Table (4): Relation between CDAS about anxiety level towards covid-19 among Primigravida and Multigravida pregnant women.

\begin{tabular}{|l|c|c|c|c|c|c|}
\hline \multirow{2}{*}{ CDAS anxiety level } & \multicolumn{2}{|c|}{ Primigravida (150) } & \multicolumn{2}{|c|}{ Multigravida (150) } & \multirow{2}{*}{ X2 } & \multirow{2}{*}{ p-value } \\
\cline { 2 - 5 } & No & $\mathbf{\%}$ & No & \% & & \\
\hline - Mild & 12 & 8.0 & 10 & 7.0 & \multirow{2}{*}{0.955} & \multirow{2}{*}{$0.001^{*}$} \\
\hline -Moderate & 33 & 22.0 & 65 & 43.0 & \\
\hline -Sever & 105 & 70.0 & 75 & 50.0 & & \\
\hline
\end{tabular}

*A statistically significant difference

Table (5): Relation between the average scores of the FCV-19S and CDAS.

\begin{tabular}{|l|c|c|c|c|}
\hline Items & Primigravida & Multigravida & T-test & p-value \\
\hline - FCV-19S average Scores & $28.70 \pm 5.12$ & $22.730 \pm 10.12$ & \multirow{2}{*}{17.67} & \multirow{2}{*}{$0.000 * * *$} \\
\hline - CDAS average Scores & $39.60 \pm 13.50$ & $33.650 \pm 10.50$ & & \\
\hline
\end{tabular}

***A highly statistically significant difference $(P<0.000)$

Table (6): Relation between socio-demographic characteristics and the Corona disease anxiety scale average scores among the studied pregnant women

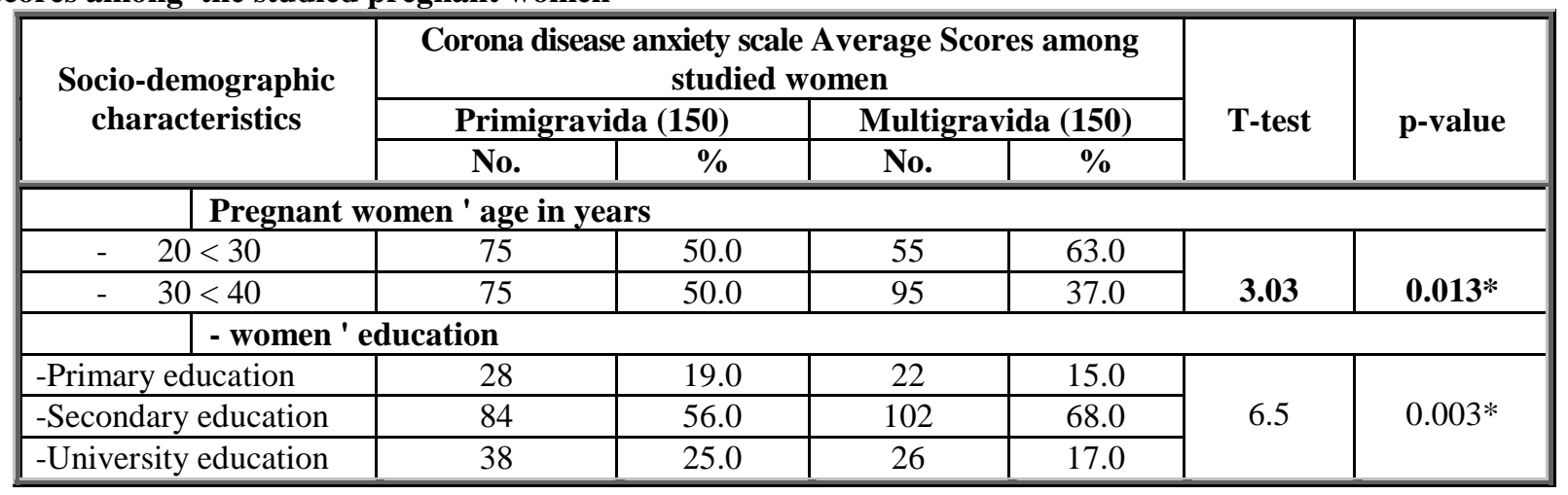




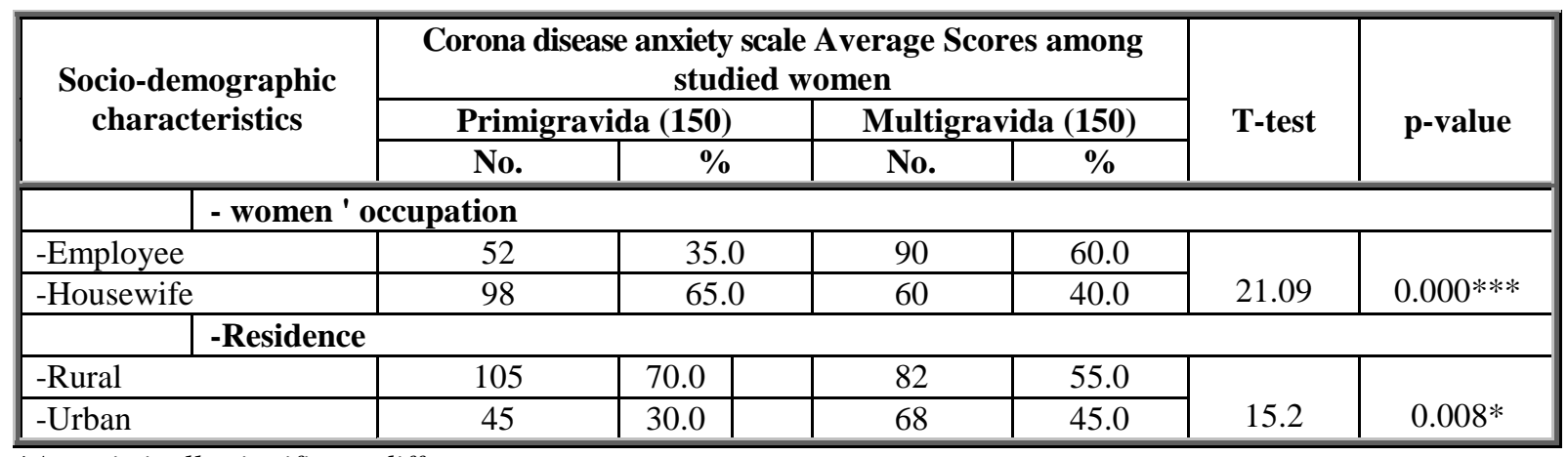

*A statistically significant difference

Table (7): Relation between sociodemographic characteristics and the FCV-19S average scores among studied pregnant women.

\begin{tabular}{|c|c|c|c|c|c|}
\hline \multirow{3}{*}{$\begin{array}{c}\text { Sociodemographic } \\
\text { characteristics }\end{array}$} & \multicolumn{4}{|c|}{ FCV-19S average Scores among studied pregnant women } & \multirow{3}{*}{ p-value } \\
\hline & \multicolumn{2}{|c|}{ Primigravida (150) } & \multicolumn{2}{|c|}{ Multigravida (150) } & \\
\hline & No. & $\%$ & & $\%$ & \\
\hline \multicolumn{6}{|c|}{ Pregnant women ' age in years } \\
\hline$-20<30$ & 75 & 50.0 & 55 & 63.0 & \multirow[t]{2}{*}{$<0.001$} \\
\hline$-\quad 30 \leq 40$ & 75 & 50.0 & 95 & 37.0 & \\
\hline \multicolumn{6}{|l|}{ women ' education } \\
\hline -Primary education & 28 & 19.0 & 22 & 15.0 & \multirow{3}{*}{$0,000 *$} \\
\hline -Secondary education & 84 & 56.0 & 102 & 68.0 & \\
\hline -University education & 38 & 25.0 & 26 & 17.0 & \\
\hline \multicolumn{6}{|l|}{ women ' occupation } \\
\hline -Employee & 52 & 35.0 & 90 & 60.0 & \multirow{2}{*}{$0.001 *$} \\
\hline -Housewife & 98 & 65.0 & 60 & 40.0 & \\
\hline \multicolumn{6}{|l|}{ Residence } \\
\hline -Rural & 105 & 70.0 & 82 & 55.0 & \multirow{2}{*}{$0.021 * *$} \\
\hline -Urban & 45 & 30.0 & 68 & 45.0 & \\
\hline
\end{tabular}

*A statistically significant difference

Table (8): multivariable-adjusted regression about the association between sociodemographic characteristics of the studied pregnant women regarding their anxiety and fear

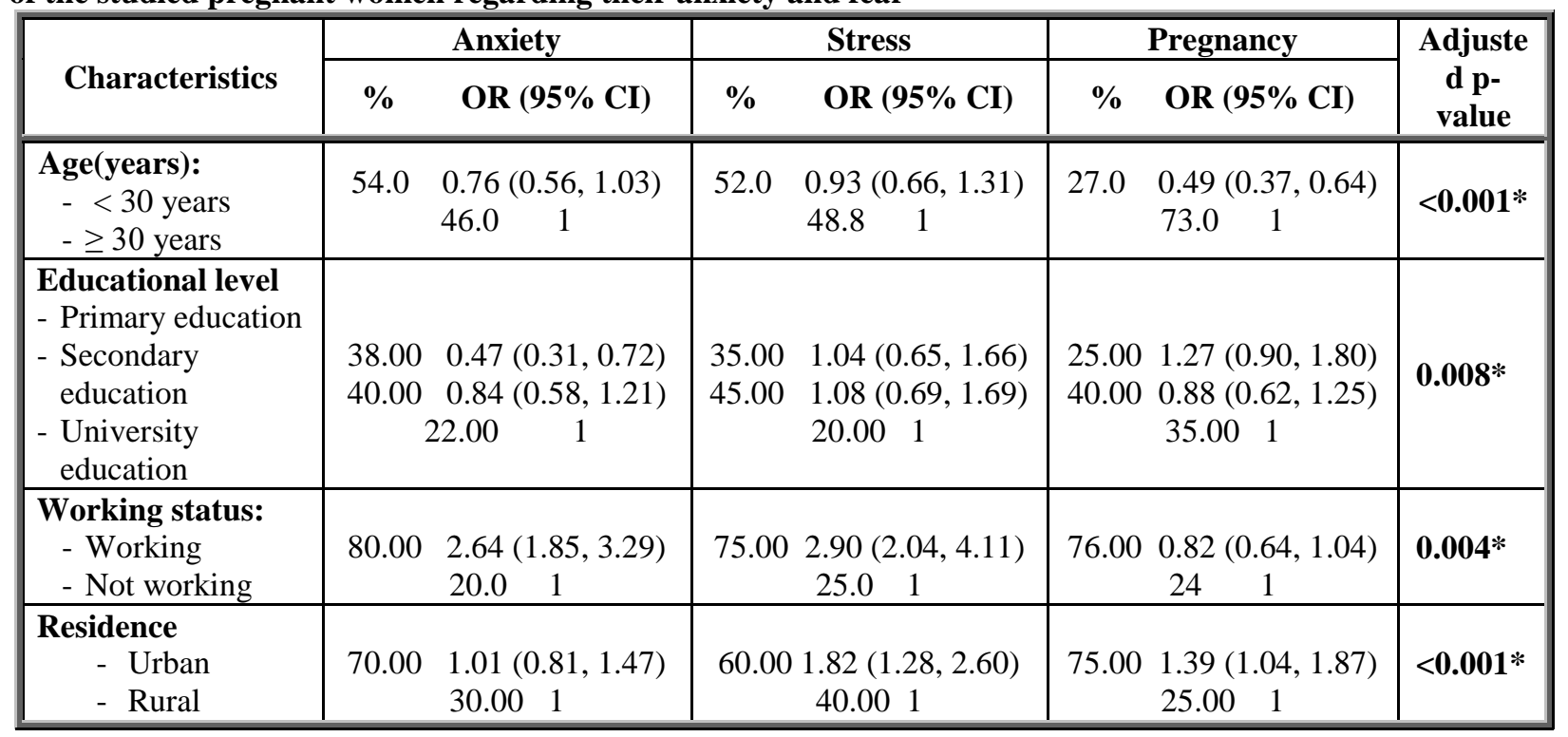

*A statistically significant difference 
Table (1): Distributes socio-demographic characteristics of the studied pregnant women. It was observed that pregnant women' age ranged from 20 33 years, and that $(50.0 \%)$ of the pregnant women their age was ranged between $20<30$ years in primigravida and their mean age \pm SD $(20.10 \pm 7.68)$ and $(37.0 \%)$ of multigravida their mean age \pm SD was $(22.10 \pm 9.88)$. Regarding the level of education, it was observed that more than half of them $(56.0 \%)$ of the primigravida pregnant women had secondary education compared to $(68.0 \%)$ of the multigravida pregnant women.

Concerning the percentage distribution of the studied pregnant women according to their occupation, Figure (1): Pointed out that $(65.0 \%)$ of primigravida pregnant women were housewives compared to $(40.0 \%)$ multigravida pregnant women.

Figure (2): Mentioned the Percentage distribution of pregnant women according to their residence and showed that rural residence was more $(70.0 \%)$ in primigravida pregnant women compared to (55.0) in multigravida pregnant women.

Table (2): Showed that all of the primigravida pregnant women didn't have obstetrical history compared to $(7.0 \%)$ only of multigravida pregnant women had an obstetrical history.

The present study in Figure (3): Illustrated the percentage distribution of pregnant women according to their history of abortion and showed that $(10 \%)$ of the multigravida pregnant women had a history of abortion compared to $(5 \%)$ of primigravida pregnant women.

Concerning mean scores and standard deviations among primigravida and multigravida pregnant women for the FCV-19S Table (3): Showed that there was a statistically significant difference between primigravida and multigravida pregnant women regarding the FCV-19S scale at value $(\mathrm{P}=0.000)$.

Table (4): Illustrated that majority of primigravida pregnant women $(70 \%)$ had severe anxiety score and $(22 \%)$ of them were moderate anxiety and $8 \%$ had mild anxiety score towards covid-19 compared to multigravida pregnant women where $(50 \%)$ had severe anxiety score and $(43 \%)$ of them had moderate anxiety and $7 \%$ of them had mild anxiety score towards covid- 19 .

Table (5): Illustrated that the average scores of the CDAS and FCV-19S, and it was displayed that significant differences were observed between the level of FCV-19S and CDAS scores $(p=0.000$ $<0.05)$ respectively. And observed that, the FCV-19S average score was $(28.70 \pm 5.12)$ in the primigravida pregnant women compared to $(22.730 \pm 10.12)$ in the multigravida pregnant women, the CDAS average score was $(39.60 \pm 13.50)$ in primigravida pregnant women compared to $(33.650 \pm 10.50)$ in multigravida pregnant women.

Table (6): Reported a relation between sociodemographic characteristics and the CDAS average scores among the studied pregnant women, it was observed that statistical significant relations were found in both groups as regard age, women ' education, women ' occupation, and residence ( $\mathrm{P}=$ $0.013, p=0.03, p=0.000=$ and $P=0.008$ ) respectively. Regarding relation between sociodemographic characteristics and the FCV-19S average scores among studied pregnant women Table (7): Displayed that statistical significant relation were found in both groups as regard age, women ' education, women ' occupation, residence $(\mathrm{P}=0,545$, $\mathrm{p}=0.000=\mathrm{p}=0,603, \mathrm{P}=0,022)$ respectively.

Table (8): Illustrated multivariable-adjusted regression about the association between sociodemographic characteristics of the studied pregnant women regarding their anxiety and fear and revealed that there was a highly statistically significant relationship detected between all sociodemographic characteristics and anxiety and fear mean scores \pm SD among pregnant women regarding their pregnancy at covid-19 pandemic $(r=0.001, r=$ $0.008, \mathrm{p}=0.004, \& \mathrm{p}=0.001)$ respectively.

\section{Discussion}

The present study revealed that the level of anxiety during pregnancy among pregnant women high in the primigravida pregnant women as compare to multigravida pregnant women, from the researcher point of view this may due to that primigravida pregnant women have no experience with the obstetrical topic and afraid from complications for the first unborn baby. These results were following the results conducted by Ningthoujam et al., (2018) who studied the level of anxiety towards childbirth among primigravida and multigravida mothers and found the same.

The current study pointed out that about two-thirds of the primigravida pregnant women were housewives; this may be the cause of increasing fear and anxiety because they could not go to medical services for counseling. More than two-thirds of the primigravida pregnant women are living in rural areas compared to more than half of multigravida this may be due to cultures and values that inhabit women in the rural area to go to antenatal clinics that cause increasing fear and anxiety.

The current study revealed that there was a statistically significant difference between the primigravida and multigravida pregnant women regarding the FCV-19S scale. This is because childbirth increased the anxiety and fear of pregnant women additionally fears and anxiety increase with 
and due to the presence of covid -19 during pregnancy. This result was similar to the study conducted by Forough \& Jila, (2018) that studied childbirth fear and associated factors in a sample of pregnant Iranian women and reported that a high level of childbirth fear was reported among pregnant Iranian women.

The current study revealed that the majority of the primigravida pregnant women had severe anxiety scores towards covid-19 compared to the multigravida pregnant women and had more anxiety where half of them had severe anxiety scores towards covid-19. This may be attributed to fear about their health and unborn babies to have complications.

The present study results clarified that significant differences were observed between the level of FCV$19 \mathrm{~S}$ and CDAS scores $(\mathrm{p}=0.000<0.05)$. And observed that, the FCV-19S average score was high $(28.70 \pm 5.12)$ in primigravida pregnant women compared to $(22.730 \pm 10.12)$ in multigravida pregnant women, the CDAS average score also was high $(39.60 \pm 13.50)$ in primigravida pregnant women compared to $(33.650 \pm 10.50)$ in multigravida pregnant women this may be due to primigravida pregnant women had more frightened about their first and first unborn babies than multigravida pregnant women. Also, these results were in the same line with Ningthoujam et al., (2018) who conduct interviews with 43 primigravida and multigravida pregnant women on the 3rd trimester during their checkup at Puskesmas and testing the difference in the level anxiety between the primigravida and the multigravida and indicating that there were differences in anxiety levels between the primigravida and the multigravida pregnant women.

The current study results displayed that statistically significant relations were found in both groups between FCV-19S, CDAS, and sociodemographic characteristics as regard age, women's education, women's occupation, residence. This is explained by that anxiety and fear is a common problem among all pregnant women especially with natural disaster as a covid-19 pandemic. These results were supported by Daglar \& Nur (2014) who studied the relationship between anxiety and depression levels and stress coping strategies of the pregnant women and mentioned that there is an association between and anxiety scores of the pregnant women with their education level.

A study showed that health crises as COVID-19 may increase fear and anxiety Wang et al., (2020). The current COVID-19 pandemic has caused the increased fear among pregnant women because they think about their unborn babies and their health condition, so COVID-19 anxiety can also be considered as an influential factor in mental health
(Corbett et al., 2020). Other results of this study showed that fear and anxiety caused by coronavirus had a direct impact on pregnant women during pregnancy (Leili et al., 2020).

Ahorsu et al., (2020), reported that pregnancy fear and anxiety is an important disease that leads to harmful outcomes during pregnancy that increases with the COVID-19 pandemic also harmed their mental health. Also, the results of a study showed that at the time of suffering from COVID-19, pregnant women reported negative emotions such as fear and anxiety (Fakari \& Simbar, 2020).

Many studies have also mentioned that during public health emergencies as COVID-19 several negative emotional disorders such as severe levels of fear and anxiety have been occurred (Zhu, 2020). This is May attributed to fear and anxiety that has increased during the pandemic period of COVID-19 (Colizzi et al., 2020). Fear and anxiety caused by corona during pregnancy would affect the mental health of pregnant women during pregnancy (Leili et al, 2020).

The results of some studies reported that women usually are more afraid of COVID-19 than men that can be due to the gender differences in sensitivity and susceptibility to fear and anxiety, and the increased risk of mental health problems following the occurrence of stressful life events (Bitan et al., 2020; Limcaoco, \& Roncero (2020). Also, the results of a previous study reported that the occurrence of the COVID-19 pandemic caused negative emotions for pregnant women (Li et al., 2020).

The current study revealed that socio-demographic characteristics of the studied pregnant women affect the psychological status and their pregnancy; In the multivariable-adjusted regression model, mothers' age, working, residence associated with a high prevalence of psychological disturbances that mothers reported anxiety (OR 1.39, 95\% CI 1.09, 1.78), fear (OR 2.64, 95\% CI 1.85, 3.29. pregnancy was also associated with anxiety and fear. That can be explained by that mothers with young age had little knowledge about the disease that made them more stressed about their unborn babies who are maybe at high risk for infection when they are born.

This is explained by the important role of community health and obstetric nurses in providing health education and counseling for the pregnant women to support them during covid -19 which result and emphasized the importance of the readiness of pregnant women to gain more information about childbirth and also covered all identified needs and knowledge gaps about the topic among the pregnant women. Because it is considered alarming as it represents insufficient health information regard this health topic and informs the need for counseling to increase health information among the pregnant 
women to be knowledgeable and may decrease anxiety and fear of unborn baby during covid-19.

\section{Conclusion}

It was found the majority of the primigravida pregnant women are experienced severe anxiety and fear scores related to covid-19 compared to multigravida pregnant women.

There was a significant positive relation at the level of $p=0.000(<0.05)$ between FCV-19S and CDAS total score among the primigravida pregnant women towards covid-19 compared to the multigravida pregnant women.

\section{Recommendation}

- Prepare pregnant women by providing them with a well-planned health program to improve their knowledge deficiency about covid-19 and providing strategies for early diagnosis and possible interventions is essential to support psychological adjustment, to prevent the complications of emotional disorders, and to improve prenatal care services.

- Study can be applied to a large sample in a different setting so that the findings can be generalized to a large population.

- Pay special attention to pregnant women's fears and anxiety to identify the mental disorders of these women during this period.

\section{References}

- Adams, S., Eberhard, M., Eskild, A., (2019): Fear of childbirth and duration of labor: a study of 2206 women with intended vaginal delivery, BJOG. 119(10):1238-46.

- Ahorsu, D., Lin, C., Imani, V., Saffari, M., Griffiths, M., \& Pakpour, A., (2020): The fear of COVID-19 scale: development and initial validation. International Journal of Mental Health and https://doi.org/10.1007/s11469-020-00270-8

- Alipour, A., Ghadami, A., Alipour, Z., \& Abdollahzadeh, H., (2020): Preliminary validation of the corona disease anxiety

- scale (CDAS) in the Iranian sample, Quarterly Journal of Health Psychology, 8 (32), 163- 175.

- Aluvihare V., Kallikourdis M., Betz A., (2004): Regulatory $\mathrm{T}$ cells mediate maternal tolerance to the fetus. Nat Immunol; 5:266-271.

- Bayrampour, H., \& Tough, S., (2015): Risk factors of transient and persistent anxiety during pregnancy. Midwifery, 31(6), 582-589.HTTPS:// doi.org/10.1016/j.midw.2015.02.2009

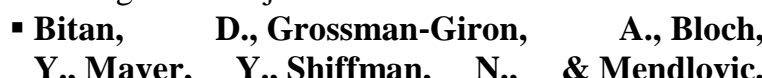

S., (2020): Fear of COVID-19 scale: Psychometric characteristics, reliability, and validity in the Israeli population. Psychiatry Research, 289, 113100.

- Brazendale, K., Beets, M., Weaver, R., Pate, R., Turner-McGrievy, G., Kaczynski, \& A., (2017): Understanding differences between summers vs. school obesogenic behaviors of children: the structured day's hypothesis. Int. J. Behav. Nutr. Phys. Act 14:100. DOI: 10.1186/s12966-017-05552

- Brooks, S., Webster, R., Smith, L., Woodland, L., Wessely, S., Greenberg, N., Rubin, G., (2020): The psychological impact of quarantine and how to reduce it: Rapid review of the evidence. The Lancet, 395(10227), 912-920. 10.1016/S01406736(20)30460-8.

- Colizzi, M., Bortoletto, R., Silvestri, M., Mondini, F., Puttini, E., Cainelli, C., Zoccante, L., (2020): Medically unexplained symptoms in the times of Covid-19 pandemic: A case report. Brain, Behavior, \& Immunity - Health, 5, 100073.

- Corbett, G., Milne, S., Hehir, M., Lindow, S., \& O'connell, M., (2020): Health anxiety and behavioral changes in pregnant women during the COVID-19 pandemic. European Journal of Obstetrics, Gynecology, and Reproductive Biology, 249 , 96. https://doi.org/10.1016/j.ejogrb.2020.04.022

- Dağlar G., \& Nur N., (2014): The relationship between anxiety and depression levels and stress coping strategies of the pregnant women. Cumhuriyet, Medicine Journal 36:429-441

- Ebadi, A., Kariman, N., \& Hajifoghaha, M., (2017): Psychometric properties and validation of the Persian translation of the pregnancy experience scale-brief version (PES). Journal of Rafsanjan University of Medical Sciences, 15 (9), 809-820.

- Fakari, F., \& Simbar, M., (2020): Coronavirus pandemic and worries during pregnancy; a letter to the Editor. Archives of Academic Emergency Medicine, 8 https://doi.org/10.22037/aaem.v8i1.598

- Feduniw, S., Modzelewski, J., Kwiatkowski, S., \& Kajdy, A., (2020): Prevalence and impact of anxiety on the mental health of pregnant women in the time of catastrophic events including COVID-19 pandemic-a rapid systematic review.

- Forough, J., \& Jila Y., ((2018): A nationwide survey of psychological distress among Chinese people in the COVID-19 epidemic: Implications and policy recommendations. General Psychiatry.; 33(2):e100213.

- Goyal, K., Chauhan, P., Chhikara, K., Gupta, P., Singh, \& M., (2020): Fear of COVID 2019: First suicidal case in India! Asian Journal of Psychiatry; 
49:101989. Doi: 10.1016/j.ajp.2020.101989. [PMC free article] [PubMed] [CrossRef] [Google Scholar]

- Hall, R., Hall, R., Chapman, \& M., (2008): Kikwit Ebola outbreak: Lessons hospitals and physicians can apply to future viral epidemics. General Hospital Psychiatry. 2008; 30(5):446-452. DOI: 10.1016/j.genhosppsych.2008.05.003.

- Hussein, J., (2020): COVID-19: What implications for sexual and reproductive health and rights globally? Taylor \& Francis.

- Leili, S., Mitra, R., Elham, M., Hamideh, Z., Sara, E., (2020): The relationship among fear and anxiety of COVID-19, pregnancy experience, and mental health disorder in pregnant women: A structural equation model

- Li, S., \& Graham, B., (2017): Why are women so vulnerable to anxiety, trauma-related, and stressrelated disorders? The potential role of sex hormones, Lancet Psychiatry; 4(1):73-82.

- Li, S., Wang, Y., Xue, J., Zhao, N., \& Zhu, T., (2020): The impact of COVID-19 epidemic declaration on psychological consequences: A study on active Weibo users. International Journal of Environmental Research and Public Health, 17(6), 2032. https://doi.org/10.3390/ijerph17062032

- Limcaoco, R., Mateos, E., Fernandez, J., \& Roncero, C., (2020): Anxiety, worry, and perceived stress in the world due to the COVID-19 pandemic, March 2020. Preliminary results. MedRxiv. https://doi.org/10.1101/2020.04.03.20043992

- Mamun, M., \& Griffiths, M., (2020): First COVID-19 suicide case in Bangladesh due to fear of COVID-19 and xenophobia: Possible suicide prevention strategies. Asian Journal of Psychiatry. 2020; 51:102073. Doi: 10.1016/j.ajp.2020.102073.

- Mehta, P., McAuley, D., Brown, M., Sanchez, E., Tattersall, R., Manson, J., \& Collaboration, H., across Specialty (2020): COVID-19: Consider cytokine storm syndromes and immunosuppression. The Lancet (London, England), 395 (10229), 1033. https://doi.org/10.1016/S0140-6736(20)30628-0

- Ningthoujam S., Priyanka S., Gulista S. and Shital K., (2018): Level of anxiety towards childbirth among primigravida and multigravida mothers, International Journal of Applied Research; 4(5): 221-224

- Qiao, J., (2020): What are the risks of COVID-19 infection in pregnant women? The Lancet, 395(10226), 760-762. 10.1016/S01406736(20)30365-2 [PMC free article]

- Qiao, Y., Wang, J., Li, J., \& Wang, J., (2012): Effects of depressive and anxiety symptoms during pregnancy on pregnant, obstetric and neonatal outcomes: A follow-up study, Journal of Obstetrics and Gynecology, 32(3), 237.240. https://doi.org/10.3109/01443615.2011.647736
- Schwartz, D., Graham, A., (2020): Potential maternal and infant outcomes from coronavirus 2019-nCoV (SARS-CoV-2) infecting pregnant women: Lessons from SARS, MERS, and other human coronavirus infections. Viruses, 12(2), 194 10. 3390/v1, 2020194.

- Vameghi, R., Amir Ali Akbari, S., Sajjadi, H., Sajedi, F., \& Alavimajd, H., (2018): A path analysis of the association between socioeconomic status, anxiety, perceived stress, social support and women's depression. International Journal of Women's Health and Reproduction Sciences, 6(3), 283-289. https://doi.org/10.15296/ijwhr.2018.47

- Wang C., Pan R., Wan X., Tan Y., Xu L., Ho C., Ho R., (2020): Immediate psychological responses and associated factors during the initial stage of the 2019 Coronavirus Disease (COVID-19) epidemic among the general population in China. International Journal of Environmental Research and Public Health. 2020; 17(5):1729. Doi: 10.3390/ijerph17051729. [PMC free article] [PubMed] [CrossRef] [Google Scholar]

- Wang, Y., Di, Y., Ye, J., \& Wei, W., (2020): Study on the public psychological states and its related factors during the outbreak of coronavirus disease 2019 (COVID-19) in some regions of China. Psychol. Health Med. 30, 1-10. Doi: 10.1080/13548506.2020.1746817

- World Health Organization (2020): Mental health and psychosocial considerations during the COVID-19 outbreak [Ebook]. Retrieved from https://www.who.int/docs/default-

source/coronaviruse/mental-health considerations .pdf.

- World Health Organization (2020): COVID-19 coronavirus pandemic, Retrieved from https://www.worldometers.info/coronavirus/

- World Health Organization. (2020): Mental health and psychosocial considerations during the COVID-19 outbreak. [Google Scholar]

- Yeniel E., \& Kavlak T., (2014): Untreated depression in the first trimester of pregnancy leads to postpartum depression: high rates from a natural follow-up study. Neuropsychiatry Dis Treat; 11:405-411.

- Yucel P., Cayir Y., \& Yucel M., (2013): Birinci trimester gebelerde depression ve anksiyete bozukluğu. Klinik Psikiyatri; 16:83-87.

- Zhu J., Sun L., Zhang L., Wang H., Fan A., Yang B., \& Xiao S., (2020). Prevalence and influencing factors of anxiety and depression symptoms in the first-line medical staff fighting against COVID-19 in Gansu. Frontiers in Psychiatry, 11, Article 386 10.3389/fpsyt.2020.00386 [PMC free article] [PubMed] [CrossRef] [Google Scholar] 